Preventive Care in Nursing and Midwifery Journal

2018; 8(4): 8-15

\title{
The Effectiveness of Stress Management and Resilience Training (SMART) on Psychological Well-Being in Patients with Thalassemia Major
}

\author{
Babaei MR ${ }^{1}$, $\underline{\text { Askarizadeh }}^{2 *}{ }^{2}$, Towhidi $\mathrm{A}^{2} \mathbb{E}$ \\ ${ }^{1}$ MSc. Dept. of Psychology, Shahid Bahonar University, Kerman, Iran \\ ${ }^{* 2} \mathrm{PhD}$. Dept. of Psychology, Associate Professor, Shahid Bahonar University, Kerman, Iran
}

*Corresponding Author: Dept. of Psychology, Associate Professor, Shahid Bahonar University, Kerman, Iran

Email: gh.askarizadeh@uk.ac.ir

Received: 16 March $2018 \quad$ Accepted: 5 Feb 2020

\begin{abstract}
Background: Thalassemia is one of the main chronic hereditary diseases characterized by severe symptoms of anemia. Also, it has negative effects on patients' mental health. However, few researches have studied the different psychiatric aspects of this disease and the psychological and social needs of thalassemic patients.

Objectives: The aim of the present study was to investigate the effect of stress management and resilience training on psychological well-being of thalassemic patients in Kerman.

Methods: This research was a quasi-experimental study using pre-test and post-test model with control group. A sample of 30 patients with thalassemia major, who referred to the Samen al-Hojaj Charity Foundation, was selected through convenience sampling and randomly divided into experimental and control groups (each group included 15 patients). After completing the pre-test, the experimental group received 10 sessions of stress management training. The instrument of the study was Reef Psychological Well-being Questionnaire (RPWB). Data were analyzed by SPSS software using covariance analysis.

Results: The results indicated that resilience and stress management training have positive effects on psychological well-being and its subscales including self-acceptance, positive relationship with others, autonomy, personal development and purposeful life of thalassemia major patients $(\mathrm{p}<0.05)$, yet it is not effective on environmental control ( $\mathrm{p}>0.05)$.

Conclusion: According to the results, regarding the effectiveness of resilience and stress management on the psychological well-being of thalassemic patients, the present study could introduce effective solution for development of psychological well-being and improvement of overall mental health of patients with thalassemia major.
\end{abstract}

\section{Keywords: resilience, stress management, psychological well-being, thalassemia major}

\section{Introduction}

Thalassemia is a genetic disorder caused by a decrease in hemoglobin in the blood [1]. In particular, the disease is highly prevalent in the Mediterranean region (Italy, Cyprus, Greece, Sicily); the Middle East (Iran, Turkey, Syria); Southeast Asia [2]. while medical treatments have helped thalassemia patients out to survive, social and psychological difficulties, provoked by the chronic nature of the disease and its invasive treatment procedure, are still substantial challenges to these patients [3], which affect patients' physical, psychological and social life negatively [4]. The hereditary nature of the disease, its outbreak in the early years of life, abnormal appearance or deformity, the expectation of premature death and necessity of sustained treatment have many negative effects on the patient, as these patients are in pain and pressure of feelings such as inferiority, despair, apprehension and distress [5]. 
There is a strong relationship between chronic illness and mental health problems which have been unexceptionally informed about thalassemia as a low chronic mental health condition [6]. In recent years, the role of psychological well-being in psychological health has received further attention [7]. Mental well-being is the consequence of a grouping of emotional adjustment, personality traits, identity, and life experiences [8]. Ryff considers psychological well-being as an emotional health which is the state of being aware of the wholeness and integrity of all existing beings [9]. It has six components including self-acceptance (the ability to observe and accept personal weaknesses and strengths), purposefulness (having motives and goals that give direction and meaning to one's life), personal development (feeling that potential talents and abilities will be activated over time), positive relationship with others (having intimate and valuable relationship with important people in life), environmental control (the ability to adjust and control living issues especially daily life) and autonomy (the ability to pursuit wishes and practice accordingly based on personal principles even if they are against the social law and tradition) [10].

An essential human ability to successfully adapt to risk factors is resilience. In medicine and psychology, resilience is defined as physical resistance and spontaneous recovery and the ability to re-establish emotional balance in stressful situations; resilience refers to features that participate in improving speed and rate of recovery after confronting stress [11]. Resilience also refers to the dynamic process of adapting positively to bitter and disastrous experiences. Refining resilience and increasing the tolerance threshold of these experiences can modify one's sense of helplessness in stressful situations and enhances his/her mood, mental and physical health [12]. Resilience training helps lessen stress and develop the use of strategies to cope with difficult situations and enhance appropriate defense mechanisms in people with stressful illnesses [10]. Individuals with high resilience indicate lower levels of avoidance that enable them cope with complications caused by illnesses. And they do not have tendency to make illness look disastrous [12]. Studies have shown that resilience has a positive relationship with social interaction, optimism, power, and functional independence [13], in contrast to negative correlation and sympathy with a range of psychological and physical pressures such as depression symptoms, post-traumatic stress disorder and physical disability [14]. In fact, resilience is the capacity of individuals to stay healthy and resist the hard and risky situations causing them not only to overcome those situations but also to grow stronger during it that may be the result of hope to the future [15].

The purpose of cognitive-behavioral stress management training is to increase the sense of control, self-efficacy, self-esteem, effective coping and social support in the individual. This reduces variations in negative moods and social isolation and promotes psychological well-being [16]. The cognitive-behavioral stress management program involves various types of behavioral techniques such as relaxation, imagination, and other anxiety-reduction techniques through typical cognitive-behavioral approaches, such as identifying negative and irrational thoughts, replacing positive logical thinking instead, having hopeful mental schemas cognitive recovery, and educating effective coping and anger management, thereby it helps enhance the parasympathetic system activation [17]. The cognitive-behavioral approach can help patients minimize the negative psychological effects of their illness [18]. Cognitive-behavioral stress management has a significant effect on cultivation of mental health status of physical patients. Studies highlight that this training lessens depression in adolescents with thalassemia major [19], increases levels of psychological well-being and recovers positive areas of health in women with HIV [13] and reduces stress, anxiety and depression in women with alopecia areata [20]. This training has also been effective in regulating biological markers of stress in low-income mothers and their infants [14], increasing psychological, emotional, and social well-being in students with homesickness [15], and enhancing the quality of life of patients with major thalassemia [16].

Although medical advances have played an important role in improving the life and longevity of people with the disease, research findings and reports on mental health in the country indicate the prevalence of psychological disorders [20]. 
Suicide, depression and anxiety (12a) are evident in these patients. Due to fact that thalassemia major is the most common hereditary anemia in many countries of the world and Iran [2] and few studies are available on the different psychiatric aspects of this disease and the counseling psychiatric and social needs of these patients, it is significant to investigate the effect of psychological therapies in reducing the symptoms of thalassemia major. Therefore, the purpose of this study was to investigate the effect of cognitive behavioral approach in stress management and resilience training on the psychological well-being of thalassemic patients in Kerman.

\section{Methods}

The present study was quasi-experimental using pre-test and post-test model with control group. The statistical population of this study included patients with thalassemia major who referred to Samen al-Hojaj Charity Institute of Kerman in 2015. Individuals diagnosed as thalassemic major were referred to the researcher and completed the prep form of demographic information (age, gender, education). Inclusion criteria consisted of: 1 - physically being able to attend meetings; 2being in the age range of 20-30 years; 3 - being educated at least in diploma; 4- residing in Kerman; 5- having no history of being in stress management workshops; 6- no using of psychiatric drugs. Finally, a list of 271 major thalassemia patients who referred to the Samen alHojaj charity and met the research criteria was prepared over one-month period. According to the method of sample size determination in behavioral studies, a minimum sample size of 15 people is determined for each group [21]. Thus, 30 people were selected randomly from eligible individuals.

In order to collect data in pre-test and post-test, Ryff Scales of Psychological Well-Being questionnaire was completed by experimental and control groups. The Psychological Well-Being Scale (RSPWB) was developed by Ryff \& Keyes in 1989. The original form of the scale had 120 questions, but shorter formats of 84, 54, and 18 questions were later developed and evaluated. The scale has six subscales of self-acceptance, positive relationship with others, autonomy, environmental control, personal development, and purposeful life
[22]. The reliability coefficient of this tool was reported by Reef and Keys between 0.83 and 0.91 and its reliability was 0.85 in a Khodabakhsh and Mansouri study [23]. Also, the study by Bayani et al. indicates the validity and reliability of the Persian version of this questionnaire [24]. In this study, Cronbach's alpha was 0.82 and its subscales ranged alpha from 0.70 to 0.78 . Its positive correlation with Satisfaction with Life Scale, Oxford Happiness Questionnaire and Rosenberg Self-Esteem Scale has confirmed its convergent validity [25]. The overall reliability coefficient of the Ryff Psychological Well-being Questionnaire was 0.89 .

To observe ethical principles, individuals were enlightened that the information, irrespective to the names of individuals, obtained from this study will be completely confidential. The control group was also trained after the intervention. This study has a code of ethics (E.A.95.08.02.02) in the Psychology Department of Shahid Bahonar University of Kerman. It is noteworthy that the absence of more than two sessions also led to the individual being excluded from the study and consequently from the training course. Random allocation was also performed to prevent bias in the results, and individuals were divided into two groups based on numbering 1 to 30 . The experimental group entered the training program for a period of ten weeks, 120-minute session per week. After 10 sessions of group training, both groups were evaluated again by the research instrument. It should be noted that only the experimental group received cognitive-behavioral stress management and resilience training. The cognitive-behavioral model presented by Antoni et al. [26] was applied to adjust the intervention model [26]. After evaluating the patients and making sure they were eligible to participate in the study, training sessions were carried out with the collaboration of the therapist. Stress coping strategies were taught to patients in this intervention. The description of the sessions is shown in Table 1. Sessions were held in this way that first, subject and the logic of the subject were elucidated by the therapist, then the members shared their views and experiences, and eventually members were asked about their viewpoint and the usage that they learned from their training. The method of this course was based on training and practice as each participant 
was asked to perform the exercises during the week until the next session. Data were analyzed using ANCOVA analysis of covariance by SPSS software.

\section{Table 1: The Content of Training Sessions}

\begin{tabular}{|c|c|}
\hline Session & the Content of Training Sessions Provided \\
\hline First & $\begin{array}{l}\text { justification and necessity of resilience and management: introduction to stressors and stress responses, } \\
\text { gradual muscle relaxation for } 16 \text { muscle groups }\end{array}$ \\
\hline Second & $\begin{array}{l}\text { stress and awareness: exercises to develop awareness of stressful sources, physical symptoms of stress, } \\
\text { the effects of stress, the concept of resilience, understanding the impact of individual assessment of } \\
\text { stressful situations, gradual muscle relaxation for } 8 \text { muscle groups, diaphragmatic breathing, mental } \\
\text { imagery }\end{array}$ \\
\hline Third & $\begin{array}{l}\text { automatic thoughts and cognitive distortions: association of thoughts and emotions, introduction to } \\
\text { automatic thoughts and self-talks, introduction to cognitive distortions, identification of negative thoughts, } \\
\text { cognitive reconstruction, gradual muscle relaxation for } 4 \text { muscle groups, diaphragmatic breathing, mental } \\
\text { imagery }\end{array}$ \\
\hline Fourth & $\begin{array}{l}\text { substitutions for automatic thoughts: more understanding of cognitive distortions and negative thoughts, } \\
\text { introduction to the types of self-talk, understanding the stages of logical thought substitution, passive } \\
\text { gradual muscle relaxation, the combination of diaphragmatic breathing and mental imagery }\end{array}$ \\
\hline Fifth & $\begin{array}{l}\text { coping (Part 1): understanding the concept of coping, introduction to the types of coping, learning how to } \\
\text { apply coping styles to situations, self-taught training for heaviness and warmness }\end{array}$ \\
\hline Sixth & $\begin{array}{l}\text { coping (Part 2): understanding the steps to adapt coping styles to situations, relaxation through prompting, } \\
\text { diaphragmatic breathing }\end{array}$ \\
\hline Seventh & $\begin{array}{l}\text { anger management: developing awareness of anger and its different symptoms and expression patterns, } \\
\text { identifying the causes of anger and anger management strategies, mantra meditation }\end{array}$ \\
\hline Eighth & $\begin{array}{l}\text { training how to express: introducing interpersonal communication styles, different types of expressive } \\
\text { styles, understanding expressive barriers, breath counting meditation }\end{array}$ \\
\hline Ninth & $\begin{array}{l}\text { social support: introduction to definition and benefits of social support, understanding different sources of } \\
\text { social support, breath counting meditation }\end{array}$ \\
\hline Tenth & $\begin{array}{l}\text { Summary: evaluating training content progress, reviewing and extending skills learned in previous } \\
\text { sessions }\end{array}$ \\
\hline
\end{tabular}

\section{Results}

Table 2 reports separately the results of demographic characteristics in the experimental and control groups. The similarity of demographic characteristics was assessed by U Mann-Whitney test. The results indicated that there is not significant difference between two groups in age characteristic p $>0.05$; $\mathrm{M}_{\mathrm{WU}}=101.500 / \mathrm{Wilcox} \operatorname{con}=221.00$; education $\mathrm{p}>0.05 ; \mathrm{M}_{\mathrm{WU}}=106.50 / \mathrm{Wilcoxcon}=226.50$.

Table 2: Demographic Characteristics in Two Groups

\begin{tabular}{cccccc}
\hline \multirow{2}{*}{ Group } & \multicolumn{2}{c}{ age } & \multicolumn{3}{c}{ education } \\
\cline { 2 - 6 } & $\mathbf{2 0 - 2 5}$ & $\mathbf{2 6 - 3 5}$ & Diploma & B.A. & M.A \\
\hline Experimental & 8 & 7 & 7 & 5 & 3 \\
\hline Control & 10 & 5 & 6 & 7 & 3 \\
\hline
\end{tabular}

According to the normality of the data, which was confirmed by Shapiro-Wilk test, and homogeneity of variances in pre-test and post-test, analysis of covariance was used for data analysis. Descriptive statistics of pre-test and post-test scores of variable psychological well-being and its components are presented in Table 3 . 
Table 3: Descriptive Statistics of Pre-test and Post-test Scores of Variable Psychological Well-being and its Components in Experimental and Control Groups

\begin{tabular}{|c|c|c|c|}
\hline & & Pre-test & Post-test \\
\hline Variable & Group & $\begin{array}{c}\text { Mean } \pm \text { Standard of } \\
\text { Deviation }\end{array}$ & $\begin{array}{l}\text { Mean } \pm \text { Standard } \\
\text { of Deviation }\end{array}$ \\
\hline \multirow{2}{*}{ Psychological Well-Being } & Control & $324.93 \pm 33.22$ & $329.66 \pm 29.14$ \\
\hline & Experimental & $329.67 \pm 44.75$ & $371.8 \pm 32.08$ \\
\hline \multirow{2}{*}{ Self-acceptance } & Control & $51.73 \pm 10.25$ & $53.33 \pm 8.75$ \\
\hline & Experimental & $49.6 \pm 10.301$ & $60.73 \pm 9.42$ \\
\hline \multirow{2}{*}{$\begin{array}{c}\text { Positive relationships } \\
\text { with others }\end{array}$} & Control & $54.13 \pm 7.64$ & $55.13 \pm 7.42$ \\
\hline & Experimental & $55.6 \pm 9.63$ & $62.33 \pm 8.17$ \\
\hline \multirow{2}{*}{ Autonomy } & Control & $49 \pm 6.35$ & $50.93 \pm 6.05$ \\
\hline & Experimental & $51.53 \pm 7.65$ & $60.6 \pm 7.18$ \\
\hline \multirow{2}{*}{ Environmental Control } & Control & $54.07 \pm 9.45$ & $54.79 \pm 7.62$ \\
\hline & Experimental & $55.8 \pm 11.97$ & $61.06 \pm 9.84$ \\
\hline \multirow{2}{*}{ Personal Development } & Control & $58.2 \pm 8.21$ & $59.33 \pm 7.47$ \\
\hline & Experimental & $58.93 \pm 7.89$ & $63.86 \pm 6.18$ \\
\hline \multirow{2}{*}{ Purposeful life } & Control & $56.07 \pm 7.90$ & $56.53 \pm 7.48$ \\
\hline & Experimental & $56.4 \pm 6.67$ & $61.6 \pm 5.76$ \\
\hline
\end{tabular}

The results of covariance analysis showed that the effect of cognitive-behavioral stress management and resilience training on the intervention group on post-test scores of six components of psychological well-being as well as the total score (psychological well-being) was significant. The results of cognitive-behavioral stress management and resilience training on scores of selfacceptance component in the post-test indicated that the difference between the two groups was significant. According to ETA 0.64 percent, this difference exclusively can be explained by stress management and resilience training in cognitivebehavioral approach; $\mathrm{P} \leq 0.001, \eta_{\mathrm{p}}^{2}=0.64, \mathrm{~F}=12.86$. Follow-up analysis showed increase in mean of self-acceptance component in the post-test phase (60.9 \pm 73.42$)$ compared to the control group (53.08 \pm 33.75$)$. The component of positive relationships with others indicated a significant difference between the two groups. Based on ETA 0.47 percent, this difference can be explained exclusively by stress management and resilience training by cognitive-behavioral approach; $\mathrm{P}$ $\leq 0.05, \eta_{\mathrm{p}}^{2}=0.47, \mathrm{~F}=8.12$. Follow-up analysis of mean difference of positive relationship with others in post-test showed also increase in experimental group $(62.8 \pm 33.17)$ compared to control group (55.7 \pm 13.42$)$. Autonomy is another component of psychological well-being that indicated a significant difference between the two groups. Based on the ETA 0.29 percent, this difference can be explained exclusively by stress management and resilience training through cognitive-behavioral approach; $\mathrm{P} \leq 0.05, \eta_{\mathrm{p}}^{2}=0.29$, $\mathrm{F}=5.49$. Follow-up analysis of the mean difference of autonomy component in the post-test showed an increase in the experimental group $(60.7 \pm 6.18)$ compared to the control group (50.6 \pm 93.05$)$. The environmental control component was the only component of psychological well-being that the experimental $(61.9 \pm 06.84)$ and control $(54.7 \pm 79.62)$ groups indicated no significant differences in the post-test phase; $\mathrm{P} \geq 0.05, \eta_{\mathrm{p}}^{2}=0.11, \mathrm{~F}=7.40$.

The analysis of other cognitive-behavioral components also showed that the personal development component indicated a significant difference. According to ETA 0.59 percent, this difference exclusively can be explained by stress management and resilience training in cognitivebehavioral approach; $\mathrm{P} \leq 0.05, \eta_{\mathrm{p}}^{2}=0.59, \mathrm{~F}=17.81$. Follow-up analysis showed increase in mean of personal development component in the post-test phase (63.6 \pm 86.18$)$ compared to the control group (59.7 \pm 33.47$)$. Also, the component of purposeful life indicated a significant difference between the two groups. Based on ETA 0.39 percent, this difference can be explained exclusively by stress management and resilience training by cognitivebehavioral approach; $\mathrm{P} \leq 0.05, \eta_{\mathrm{p}}^{2}=0.39, \mathrm{~F}=13.76$. Follow-up analysis of mean difference of purposeful life in post-test showed also increase in experimental group $(61.5 \pm 6.76)$ compared to control group (56.7 \pm 53.48$)$. Finally, evaluation of overall score of psychological well-being indicated that there is significant difference 
between tow groups in overall score. Based on the ETA 0.58 percent, this difference can be explained exclusively by stress management and resilience training through cognitive-behavioral approach; $\mathrm{P} \leq 0.05, \eta_{\mathrm{p}}^{2}=0.58, \mathrm{~F}=8.39$. Follow-up analysis of the mean difference of personal development component in the post-test showed an increase in the experimental group (371.8 \pm 32.08$)$ compared to the control group (329.29 \pm 66.14$)$

Table 4: Covariance Analysis of the Effectiveness of Stress Management and Resilience Training on Psychological Well-being and Related Variables

\begin{tabular}{|c|c|c|c|c|c|c|c|c|}
\hline $\begin{array}{c}\text { Source of } \\
\text { Variations }\end{array}$ & $\begin{array}{c}\text { Source of } \\
\text { Variations }\end{array}$ & Subscale & $\begin{array}{c}\text { Sum of } \\
\text { Squares }\end{array}$ & $\begin{array}{c}\text { Degrees of } \\
\text { freedom }\end{array}$ & $\begin{array}{c}\text { Mean } \\
\text { squares }\end{array}$ & $\mathbf{F}$ & Significance & $\begin{array}{c}\text { Eta } \\
\text { square }\end{array}$ \\
\hline \multirow{7}{*}{$\begin{array}{l}\text { Group Or } \\
\text { Intervention }\end{array}$} & Self-acceptance & 278.67 & 278.67 & 1 & 278.67 & 12.86 & 0.009 & 0.648 \\
\hline & $\begin{array}{c}\text { Positive } \\
\text { relationships } \\
\text { with others }\end{array}$ & 116.67 & 116.67 & 1 & 116.67 & 8.12 & 0.019 & 0.474 \\
\hline & Autonomy & 40.33 & 40.33 & 1 & 40.33 & 5.49 & 0.036 & 0.0297 \\
\hline & $\begin{array}{c}\text { Environmental } \\
\text { Control }\end{array}$ & 14.88 & 14.88 & 1 & 14.88 & 7.408 & 0.283 & 0.114 \\
\hline & $\begin{array}{c}\text { Personal } \\
\text { Development }\end{array}$ & 53.77 & 53.77 & 1 & 53.77 & 17.81 & 0.001 & 0.598 \\
\hline & Purposeful Life & 68.64 & 68.64 & 1 & 68.64 & 13.763 & 0.016 & 0.393 \\
\hline & Total Score & 1980.25 & 1980.25 & 1 & 1980.25 & 8.392 & 0.027 & 0.583 \\
\hline
\end{tabular}

\section{Discussion}

The aim of this study was to investigate the effect of stress management and resilience training on the psychological well-being of thalassemic patients in Kerman. Results revealed that stress management and resilience training was effective on refining and developing self-acceptance, positive relationship with others, autonomy, personal development, purposeful life, and psychological well-being in patients with thalassemia, yet ineffective on environmental control. Finding of this study is in line with the results of Hashem Zehi et al. [27] study as they indicated that stress management treatment enhances the quality of life and anxiety management in patients with thalassemia. The findings of this study are also consistent with the studies of of Wood et al. (9), Sharma et al. (10), Urizar et al. (14), Ghanbari et al. (15), Dehghani et al. (20), Antony et al. (26), who reported stress management and resilience treatment in improving the psychological symptoms of chronic diseases.

Regarding the disease conditions and the limitations that disease imposes on the patient can lead to a feeling of helplessness. On the other hand, resilience increases patient's tolerance threshold in stressful situations and adjusts feeling of helplessness [9]. One of the reasons for the effect of stress management treatment on the psychological well-being of patients is the reduction of feeling of helplessness in thalassemic patients. Studies also show that this training makes one apply more appropriate coping strategies in stressful situations [10]. And as more effective coping strategies are associated with higher well-being levels. Another effective mechanism of resilience training on improving the psychological well-being of patients with thalassemia is its help in finding more compatible coping strategies. In addition, resilience enhances one's inner and mental capacity to withstand stressful situations in a way that not only one is enabled to overcome those problematic conditions but also increase his/her hope for the future [28], thereby raising the feeling of hopefulness for the future in the person can be another reason for effectivity of training in increasing the level of psychological well-being of patients with thalassemia.

According to Peronian et al. [29], group training based on relaxation and stress management in patients with thalassemia can reduce depression and improve self-esteem in these patients. Given that lower depression and higher self-esteem contribute, respectively, to mental health and psychological well-being in patients with thalassemia [30,31]; the findings of this study can also be explained and suggested accordingly as stress management and resilience training help to improve various aspects of psychological wellbeing by reducing depression and improving selfesteem in thalassemic patients. Also, regarding the fact that cognitive-behavioral stress 
management treatment refers to a family of stress management treatments that concentrate on the cognitive-behavioral approach. Stress management increases individuals' ability to adapt to stressful situations [10], and help patients minimize the negative psychological effects of their illness [32]. Concerning research findings on the effectiveness of cognitive-behavioral approach to stress management and resilience training on psychological well-being components, it can be noted that stress management and resilience skills can guide personal, interpersonal and environmental actions in a way that result in healthier life. Therefore, when the patient reviews his/her life, he is not to worry too much about what is happening to him/her in life concerning his actions and behaviors and feel positive and confidant about himself/herself.

Therefore, it can be said that stress management and resilience training increase individuals' ability to reduce stress and adapt to stressful situations. This intervention consists of elements such as increase in stress awareness, relaxation training, identification of inappropriate thoughts, cognitive reconstruction, problem solving training, self-expression skills training, anger management, self-management, and activity planning. They promote the psychological wellbeing of patients, so individuals with a high sense of well-being experience mainly positive emotions and have positive evaluations of events around them. In order to increase the mental health and psychological well-being of these patients, such interventional measures are necessary. These social support interventions can be used as a comprehensive and effective tool for rehabilitation of patients with thalassemia major.

\section{Acknowledgments}

We would like to thank all the patients with thalassemia who helped us with this study.

\section{Conflict of interest}

This research is not in conflict with the interests of any organization or institution.

\section{References}

1. Taher AT, Weatherall DJ, Cappellini MD. Thalassaemia. Lancet. 2018; 391(10116): 155-67.

2. Ahmadpanah M, Asadi Y, Haghighi M, Haghighi M, Ghasemibasir H, Khanlarzadeh E,
Brand S. In patients with minor beta-thalassemia, cognitive performance is related to length of education, but not to minor beta-thalassemia or hemoglobin levels. Iran J psychiatry. 2019; 14(1): 47-53.

3. Lyrakos GN, Vini D, Aslani H, Drosou-Servou M. Psychometric properties of the Specific Thalassemia Quality of Life Instrument for adults. Patient Prefer Adherence. 2012; 6: 477-97.

4. Yahia S, El-Hadidy MA, El-Gilany AH, Anwar R, Darwish A, Mansour AK. Predictors of anxiety and depression in Egyptian thalassemic patients: a single center study. Int J Hematol. 2013; 97(5): 604-609.

5. Khoury B, Musallam KM, Abi-Habib R, et al. Prevalence of depression and anxiety in adult patients with $\beta$-thalassemia major and intermedia. Int J Psychiatry Med. 2012; 44(4): 291-303.

6. Thiyagarajan A, Bagavandas M, Kosalram K. Assessing the role of family well-being on the quality of life of Indian children with thalassemia. BMC pediatrics. 2019; 19(1): 100106.

7. Steptoe A, Deaton A, Stone AA. Psychological wellbeing, health and ageing. Lancet. 2015; 385(9968): 640-648.

8. Goldstein S, Brooks RB. Why study resilience. Handbook of Resilience in children (pp 49 - 64) New York. 2005; Contemporary Books. https://www.springer.com/gp/book/97814614366 07.

9. Wood S, Bhatnagar S. Resilience to the effects of social stress: Evidence from clinical and preclinical studies on the role of coping strategies. Neurobiol Stress. 2015; 1: 164-73.

10. Sharma V, Sood A, loprinzi C, Prasad K. Stress Management and Resilience Training (SMART) program to decrease stress and enhance resilience among breast cancer survivors: a randomized trial. BMC Complement Altern Med. 2012; 12: 211-20.

11. Jabalameli SH, Neshat-dost $\mathrm{H}$, Molavi $\mathrm{H}$. Stress Management Effectiveness of cognitive behavioral therapy on quality of life and blood pressure in hypertensive patients. J Kurdistan Univ Med Sci. 2011; 15(2): 88-97.[In Persian]

12. Kahrazei F, Danesh E, Hydarzadegan A. The effect of cognitive-behavioral therapy (CBT) on reduction of psychological Kahrazei F, Danesh symptoms among patients with cancer. Zahedan J 
Res Med Sci (ZJRMS). 2012; 14(2): 112-16. [In Persian]

13. Jensen SE, Pereira DB, Whitehead N, et al. Cognitive-behavioral stress management and psychological well-being in $\mathrm{HIV}+\mathrm{racial} / \mathrm{ethnic}$ minority women with human papillomavirus. Health Psychol. 2013; 32(2): 227-30.

14. Urizar GG, Muñoz RF. Impact of a prenatal cognitive-behavioral stress management intervention on salivary cortisol levels in lowincome mothers and their infants. Psychoneuroendocrinology. 2011; 36(10): 148094.

15. Ghanbari N, Habibi M, Shamsodini S. Effectiveness of Cognitive-Behavioral Stress Management in Promotion Psychological, Emotional, and Social well-being of Homesick University Students. J Clin Psychol. 2013; 5(1): 47-56. [In Persian]

16. Babayi MR, Askarizadeh GH, Towhidi A. The Effectiveness of Resilience Training and Stress Management (smart) on the Quality of Life in Patients With Thalassemia Major. PCNM. 2017; 7(2): 7-14.

17. Ghanizadeh A, Khajavian S, Ashkani $\mathrm{H}$. Prevalence of psychiatric disorders, depression, and suicidal behavior in child and adolescent with thalassemia major. J Pediatr Hematol Oncol. 2006; 28(12): 781-84 .

18. Kiani AA, Mortazavi Y, Zeinali S, Shirkhani Y. The molecular analysis of beta-thalassemia mutations in Lorestan Province, Iran. Hemoglobin . 2007; 31(3): 343-49.

19. Hosseini S, Khani H, Khalilian A, Vahidshahi K. Psychological Aspects in Young Adults with Beta-Thalassemia Major, control group. J Mazandaran Univ Med Sci. 2007; 17(59): 51-60. [In Persian]

20. Dehghani F, Neshat-Doust H, Molavi H, Nilforoushzadeh $M$. The Effect of CognitiveBehavioral Stress Management Therapy on Depression and Anxiety of Females with Alopecia Areata. J Clin Psychol(Iran). 2009; 1(2): 1-9 . [In Persian]

21. Delavar A. Theoric and scientific research in humanistic science. $1^{\text {st }}$ ed. Tehran: Roshd; 1995: 57. [In Persian]

22. Ryff CD, Keyes CL. The structure of psychological well-being revisited. J Pers Soc Psychol. 1995; 69(4): 719-27.
23. Khodabakhsh MR, Mansoori P. Investigation adaptive and non-adaptive aspects Humor and subjective well-Being in job burnout among nurses. J Mashsad Nurs Midwifery. 2011; 17(6): 20-31. [In Persian]

24. Bayani A, Mohammad Koochekya A, Bayani A. Reliability and Validity of Ryff's Psychological Well-being Scales. IJPCP. 2008; 14(2): 146-51. [In Persian]

25. Aghababaei N, Farahani $\mathrm{H}$. The Role of Trait Gratitude in Predicting Psychological and Subjective Well-being. Develop Pscychol. 2012; 8(29): 75-84. [In Persian]

26. Antoni MH, Lehman JM, Kilbourn KM, et al. Cognitive-behavioral stress management intervention decreases the prevalence of depression and enhances benefit finding among women under treatment for early-stage breast cancer. Health Psychol. 2001; 20(1): 20-32.

27. Hashem-Zahi S. The Effectiveness of Cognitive Behavioral Therapy on Anxiety and Quality of Life among Thalassemia Patients in Major City [Disseration]. Sistan and Baluchestan: University of Sistan and Baluchestan. 2016. [In Persian]

28. Duffy James D, Valentine Alan D. Therapeutic relationship MD Anderson manual of psychosocial oncology. 2010; New York: Hill Company.

29. Parvininasab AM, Rosta S, Vojdani MA, et al. The effect of partnership care Model on depression of adolescents with $\beta$ thalassemia. Iran J Psychiatric Nurs. 2014; 1(4): 26-35. [In Persian] 30. Babaei-Menghari MM, khaleghkhah A. Path analysis model between spiritual Health, quality of life with depression thalasemia major patients. Health Psychol. 2016; 5(17): 119-34. [In Persian] 31. Mohammadzadeh $\mathrm{H}$, BahreinianA, Mohtashami J, Shakeri N, JamshidiKhezli T. High of Esteem-Self on Therapy Cognitive Group of Effectiveness The Students Female School . Iran J Psychiatric Nurs. 2016; 4(13): 19-27. [In Persian]

32. Mevada ST, Al Saadoon M, Zachariah M, Al Rawas AH, Wali Y. Impact of Burden of thalassemia major on health-related quality of Life in omani children. J Pediatr Hematol Oncol. 2016; 38(5): 384-88. 